\title{
XXIII.-IMMUNITY STUDIES IN EXPERIMENTAL SYPHILIS
}

INFECTIVITY AND SURVIVAL OF SPIROCHAETA PALLIDA IN RABBITS, WITH OBSERVATIONS ON SOME STRAINS FROM LATENT SYPHILIS

FREDERICK EBERSON, Рн.D.

Associate in Dermatology, Washington University School of Medicine ST. Louis

Local immunity, or a better term, resistance to reinoculation in syphilis has been established as a fact both experimentally and clinically. Information is lacking with regard to the behavior of Spirochaeta pallida which have been exposed to such influences as might logically be assumed to modify the course of an infection in the animal body. It has been shown in a previous study ${ }^{1}$ that syphilis in man, when latent and outwardly inactive, can be associated with the presence of Spirochaeta pallida in the glands and in the semen. In the experimental animal this question has been approached as a control on the problem in man, and results, such as localization in certain glands and preliminary observations bearing on latency in experimental syphilis, have been recorded in another place. ${ }^{2}$ The brilliant studies of Brown and Pearce $^{3}$ which were made in connection with the therapeutic action of drugs have supported such findings independently. All phases of the problem which deal with cyclic changes in the course of infection in syphilis, the regression of lesions and the factors tending toward and modifying a condition known as latency, are intimately linked with the wider and more fundamental aspect of immunity. Whatever knowledge is to be gained from a study of the behavior of different strains of Spirochaeta pallida in animals may find some application to the

* Work done under a grant from the U. S. Interdepartmental Social Hygiene Board, Washington, D. C.

* Studies, observations and reports from the dermatological department of the Barnard Free Skin and Cancer Hospital and the Washington University School of Medicine, St. Louis, Mo., U. S. A., service of Drs. M. F. Engman and W. H. Mook.

1. Eberson, F., and Engman, M. F.: An Experimental Study of the Latent Syphilitic as a Carrier, J. A. M. A. 76:160 (Jan. 15) 1921 ; Engman, M. F., and Eberson, F.: XXI.-A Biologic Study of Latency in Syphilis, Arch. Dermat. \& Syph. 3: Pt. 1, 347 (April) 1921.

2. Eberson, F.: Dissemination of Spirochaeta Pallida in Experimental Syphilis, Arch. Dermat. \& Syph. 3:111 (Feb.) 1921.

3. Brown, W. H., and Pearce, L.: J. Exper. Med. 31:749 (June) 1920. 
solution of the general problem. This paper represents, therefore, a report of certain findings which were incidental to the immunity studies now in progress.

There are certain difficulties involved in an attempt to study factors which may be likely to alter the virulence of an infectious organism. In the first place, we have no reliable criteria by which to measure the infective power of different strains of Spirochaeta pallida. If the incubation period is to be taken as a guide, then factors such as dosage, for example, must be subject to control and others be kept constant in order that results may be comparable. When, as in the case with syphilis in the rabbit, it becomes difficult to control certain fortuitous elements, the measure of accuracy is lessened considerably. Again, the difference in individual strains of spirochetes tends to confuse the picture so that the property of generalization, which some strains may possess, cannot be relied on for the degree of virulence. To make matters more complex, this manifestation seems to be influenced further by artificial procedures which are brought to bear on the primary focus of infection, as has been shown by. Reasoner, ${ }^{4}$ and Brown and Pearce, ${ }^{5}$ and noted in our own studies.

ANIMAL PASSAGE AND ITS BEARING ON THE QUESTION OF VIRULENCE

The point of departure for the experiments which are embodied in the present report was the oft repeated opinion of most investigators that passage through animals enhances the virulence of Spirochaeta pallida. This idea was first promulgated by Uhlenhuth and Mulzer. ${ }^{6}$ Opposed to this view are the studies of Zinsser, Hopkins and McBurney, ${ }^{7}$ who found no apparent increase of infective power, although they admitted certain fluctuations due to factors in the technic which they employed. Reasoner," also, has stressed certain points which may modify the success of inoculation with material from syphilitic sources. However, with the exception of Brown and Pearce, ${ }^{8}$ investigators have ignored heretofore the possible importance of even a rough quantitative procedure in the determination of differences in virulence of strains which were used in the experiments. When it is desired to obtain successful "takes," a technic such as Brown and Pearce have described meets the requirements. For the purpose, how-

4. Reasoner, M. A.: Some Phases of Experimental Syphilis, J. A. M. A. 67: 1799 (Dec. 16) 1916.

5. Brown, W. H., and Pearce, L.: Arch. Dermat. \& Syph. 2:675 (Dec.) 1920.

6. Uhlenhuth, P., and Mulzer, P.: Arb. a. d. k. Gsndhtsamte 44:307, 1913.

7. Zinsser, H., Hopkins, J. G., and McBurney, M.: J. Exper. Med. 23:329 (March) 1916.

8. Brown, W. H., and Pearce, L.: J. Exper. Med. 31:475 (April) 1920. 
ever, of studying the survival in vivo of strains taken from experimentally infected animals, further refinements are necessary, if the period of incubation is to be taken as an index of any value. Repeated passage of Spirochaeta pallida from animal to animal is a two-phase reaction. Adaptation to the host means the subjecting of spirochetes to such mechanisms of defense and biochemical reactions as may tend to reduce virulence rather than to increase it in response to locally developed immune substances or metabolic products. From the standpoint of latency, such factors have to be kept in mind, and it is a short step to the belief that spirochetes taken from old or receding lesions would tend to show longer incubation periods when transferred to other animals. This point has been observed irregularly in our study of behavior of strains of Spirochaeta pallida, and from the methods employed we are led to believe that inoculations made from lesions of different age are not correlated with prolongation or diminution of the incubation period. Different factors, such as the strain of spirochete and the technic used, may be of more importance. If the vitality of the spirochetes is diminished by residence within a zone of the testicle, the dose of virus used should have some effect on the speed of reaction, yet this is not generally the case, even when other factors are kept relatively constant. To follow up this conception it would be necessary to prove that distinct differences exist between different "lines of descent" obtained from a series of animals which represent transfers from actively developing lesions and a series of generations derived from animals with old, regressive lesions. Each new generation would include, therefore, in series, animals which had been inoculated with Spirochaeta pallida taken early and late in the course of infection. Any true variation of the incubation period and other points of interest can be discerned by such a procedure.

\section{EXPERIMENTAL WORK}

Orgawisms Studied.-Seven strains of Spirochaeta pallida were used in the experiments to be reported. Of these, three were isolated from the inguinal glands of patients having latent syphilis, two from the semen of similar patients, and two from penile chancres in active cases. The information to be gleaned from any one strain was substantially the same for all, so that two typical examples have been selected for illustration in this paper under the heading of infectivity and survival, while the differences which may appear to exist among Spirochaeta pallida from latent sources as compared with the others will be treated separately. These two strains, described as No. 137 and No. 170 , have been isolated, respectively, from an inguinal gland of a latent syphilitic patient and from a penile chancre of a patient with an active case. They have been carried in rabbits in this laboratory for over eighteen months.

Animals Used.--Medium sized gray and brown rabbits with well developed testicles were used. As a rule, the animals were from 5 to 6 months old at the time of inoculation. 
Technic.-Emulsions of Spirochaeta pallida were prepared from material taken directly from the lesion in the testicle by means of a finely drawn out capillary glass pipet. Warm salt solution was added in a small amount to the testicular puncture fluid which was expelled into a sterile Petri dish with the aid of a rubber nipple attached to the pipet. A sterile glass rod, flattened at one end, and bent at a convenient angle, was used to grind up the sticky mass in the smallest possible volume of solution. This was next drawn up into a pipet through a thin layer of sterile absorbent cotton placed in the homogenous emulsion. The perfectly clear fluid containing the organisms free from any tissue or foreign material was then ready for injection. The suspension of spirochetes was prepared so as to average about three for each field. The material was injected in amounts of 0.5 c.c. directly into the center of the testicle by means of glass Luer syringes fitted with a 21 gage needle, $5 / 8$ inch in length.

The rabbits were examined daily after two weeks had elapsed and subinoculations were made at different intervals from the same animal as well as from a single transfer from each rabbit of any series which represented the same new generation in each instance. By means of this method frequently repeated puncture of an individual lesion was avoided and more material for continuous transfer made available from those animals which had to be punctured repeatedly in order to keep the supply of animals at a minimum. Incidentally, the procedure made it possible in some degree to overcome whatever error may prevail in an attempt to exclude the withdrawal of Spirochaeta pallida from new minute lesions which may have become localized adjacent to an original old area in the testicle. The shortcomings of technic were appreciated in this connection, and an effort was made to eliminate all possible inaccuracy. Where some degree of metastasis or extension had occurred seemingly, care was taken to avoid any other than the old area which, as a rule, regressed pari passu with the age of the lesion. Results with both methods, carefully followed, revealed no essential differences and checked reasonably accurately.

INCUBATION PERIOD AND SURVIVAL WITHIN THE RABbit TESTICLE

The persistence of Spirochaeta pallida in testicular lesions was marked by considerable variation. This variation did not seem to be associated with differences in the period of incubation, as reference to the correlation tables will show (Tables 1 and 2). Admitting the difficulty of proving the complete absence of organisms by the method of puncture and dark-field examination, a further procedure was resorted to, namely, that of inoculating new animals with emulsions of testicles which were found to be free from spirochetes. Especial effort was made to inject only clear fluid prepared in the manner described. In several instances, testicles which appeared to be normal after varying times subsequent to spontaneous disappearance of lesions, were used in this manner to determine relatively the ultimate period of survival. Excluding this group of animals for the present, the results in general may be summarized thus: Spirochaeta pallida could be demonstrated by puncture for periods ranging from one day to four and a half months 
or more, irrespective of the period of incubation, which varied as much as seven weeks beyond that of the observed minimum, namely, from 18 to 20 days. No correlation seemed to exist between a short period of incubation and a rapid disappearance of organisms and the reverse (Tables 1 and 2). As far as could be determined, there were no

Table 1.-Strain 137. Correlation-Age of Lesion, Incubation Period, SURVIVAL*

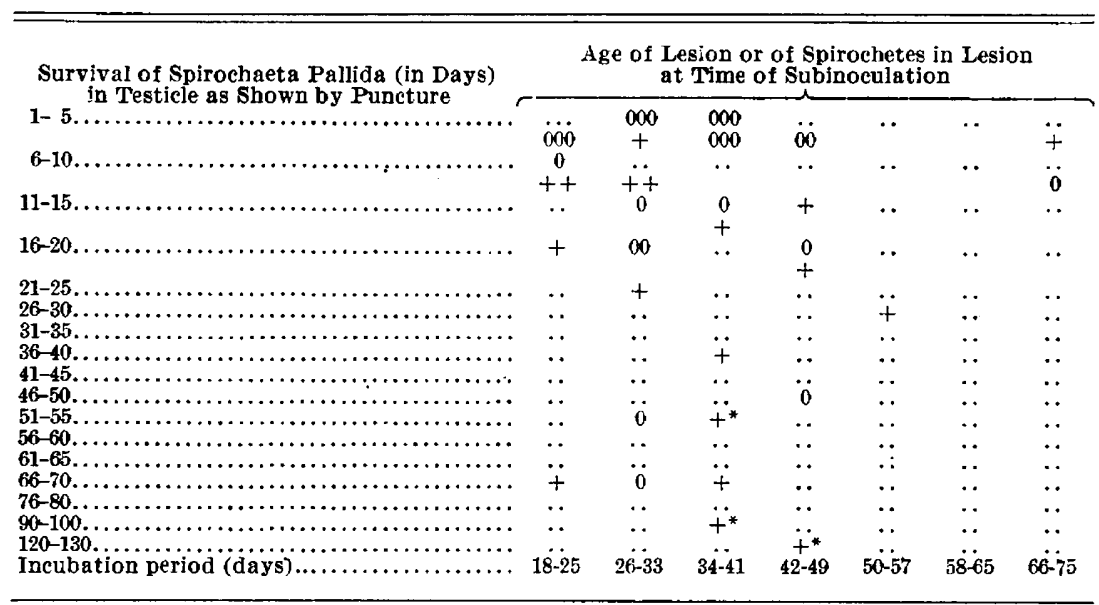

* In Tables 1 and 2 the symbols indicate individual generations of the strain; 0 , age of lesion at time of subinoculation; + , survival of Spirochaeta pallida in testicle; *, incomplete observations.

TABlE 2.-Strain 170 . Correlation-Age of Lesion, Incubation Period, SURVIVAL

\begin{tabular}{|c|c|c|c|c|c|c|c|c|c|c|}
\hline \multirow{3}{*}{ 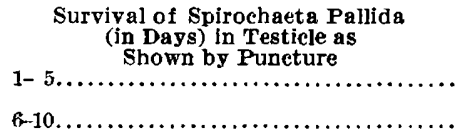 } & \multicolumn{10}{|c|}{$\begin{array}{c}\text { Age of Lesion or of Spirochetes in Lesion } \\
\text { at Time of Subinoculation }\end{array}$} \\
\hline & 000 & & 0 & & $\cdots$ & $\cdots$ & & & $\cdots$ & \\
\hline & $\stackrel{+}{0}$ & $\begin{array}{c}0 \\
000\end{array}$ & $\stackrel{+}{0}$ & 000 & t+ & . & 0 & $\begin{array}{c}0 \\
+\end{array}$ & & 0 \\
\hline${ }_{11-15}$ & + & + & ++ & . & & & •. & & & + \\
\hline 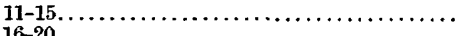 & + & $\cdots$ & $\because$ & + & $\ddot{\theta}$ & $\cdots$ & $\cdots$ & $\cdots$ & $\cdots$ & $\cdots$ \\
\hline 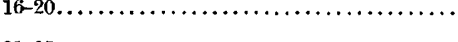 & $\begin{array}{l}000 \\
+\end{array}$ & . & $\stackrel{0}{++}$ & + & 0 & $\cdots$ & $\cdots$ & $\cdots$ & . & $\cdots$ \\
\hline 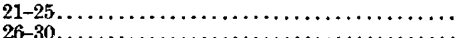 & $\therefore$ & 0 & 0 & + & 0 & . & .. & . & . & . \\
\hline $\begin{array}{l}26-30 \\
31-35 \\
31 \\
\end{array}$ & $\cdots$ & $\cdots$ & + & $\cdots$ & $\cdots$ & $\cdots$ & $\cdots$ & $\cdots$ & . & . \\
\hline $36-40, \ldots \ldots \ldots \cdots \cdots \cdots$ & $\cdots$ & $\ddot{t}$ & o & $\ddot{0}$ & $\cdot \cdot$ & $\cdots$ & • & . & . & . \\
\hline 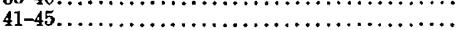 & $\ddot{+}$ & $\begin{array}{l}+ \\
.\end{array}$ & $\begin{array}{l}0 \\
0\end{array}$ & + & $\ddot{\circ}$ & $\because$ & $\because$ & $\because$ & $\because$ & $\because$ \\
\hline 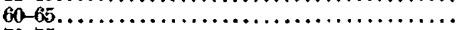 & + & $+^{*}$ & .. & .. & $\ddot{\ddot{*}}$ & $\because$ & $\ddot{+}$ & $\ddot{0}$ & $\because$ & $\because$ \\
\hline $70-75, \ldots \ldots \ldots, \ldots, \ldots, \ldots, \ldots, \ldots, \ldots$ & $\therefore$ & 0 & + & .. & .. & .. &.. &.. & .. & $\therefore$ \\
\hline Incubation period (days).......... & 18-21 & $22-25$ & $26-29$ & $30-33$ & $34-37$ & $38-41$ & $42-45$ & $46-49$ & $50-60$ & $70-75$ \\
\hline
\end{tabular}

differences to be seen in any series of animals regardless of the number of passages of the strain or the age of the lesion at the time spirochetes were taken for subinoculation. These points are shown graphically in the tables which summarize the data of different "lines of descent" (Tables 3 and 4 ). 
Table 3.--Successive Generations of a Strain of Sirochaeta Pallida from a Case of Latent Syphilis *

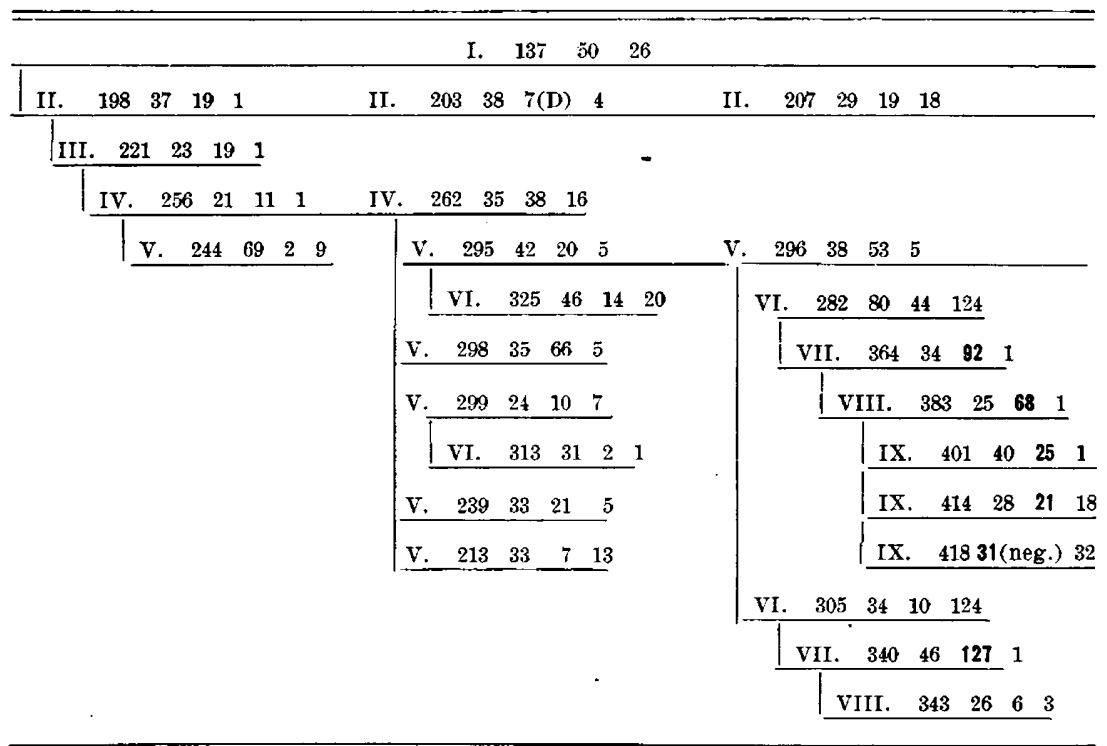

* In Tables 3 and 4 , the Roman numerals represent generations in rabbits' testicles and the flgures, reading from left to right indicate, respectively, the number of the rabbits, the incubation period in that animal, the survival of Spirochaeta pallida as found by dark-field examination of puncture material from the testicle, and the age of the lesion or of spirochetes in such lesion at the time subinoculation was made. Figures in bold face type represent incomplete observations. $\mathrm{D}=$ death.

Table 4.-Successive Generations of a Strain of Spirochaeta Pallida from Chancre in Primary Syphilis

\begin{tabular}{|c|c|c|}
\hline & I. $\quad 170 \quad 33 \quad 19$ & \\
\hline II. $\begin{array}{llll}204 & 33 & 21 & 1\end{array}$ & & II. $\quad 210 \quad 34 \quad 7 \quad 18$ \\
\hline III. $\begin{array}{llll}220 & 30 & 12 & 1\end{array}$ & & \\
\hline III. $\quad 245 \quad 26 \quad 19$ (D) 20 & 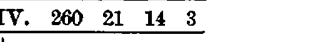 & \\
\hline 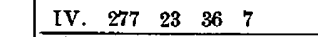 & v. $\quad \begin{array}{llll}288 & 25 & 6 & 9\end{array}$ & \\
\hline v. $\begin{array}{llll}300 & 37 & 9 & 23\end{array}$ & V. $\begin{array}{lllll}242 & 20 & 7 & 9 \\
\end{array}$ & \\
\hline v. $\begin{array}{llll}301 & 28 & 8 & 23\end{array}$ & VI. $\quad \begin{array}{llll}211 & 21 & 65 & 5 \\
\end{array}$ & \\
\hline V. $\begin{array}{lllll}315 & 28 & 74 & 34 \\
\end{array}$ & $\begin{array}{lllll}\text { VII. } \quad 319 & 29 & 28 & 6 \\
\end{array}$ & \\
\hline \begin{tabular}{|lllll} 
VI. & 223 & 30 & 43 & 38 \\
\end{tabular} & VIII. $327 \quad 43 \quad 62$ & 1 \\
\hline & $\begin{array}{lllll}\text { VII. } & 320 & 24 & 53 & 25 \\
\end{array}$ & 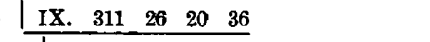 \\
\hline & VIII. $\begin{array}{rrr}235 \quad 70 \quad 10 \\
\end{array}$ & 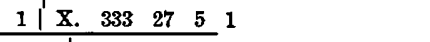 \\
\hline & & $\begin{array}{lllll}\mathrm{XI} . & 347 & 46 & 6 & 3 \\
\end{array}$ \\
\hline 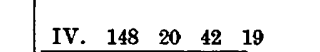 & & $\begin{array}{lllll}\text { XII. } & 373 \quad 20 & 36(\mathrm{D}) & 1 \\
\end{array}$ \\
\hline V. $\begin{array}{llll}121 & 28 & 8 & 43\end{array}$ & & $\begin{array}{lllll}\text { XIII. } & 395 & 23 & 52 & 10 \\
\end{array}$ \\
\hline $\begin{array}{lllll}\text { IV. } & 152 & 20 & 16 & 19\end{array}$ & & $\begin{array}{lllll}\text { XIII. } & 387 & 22 & 60 & 1 \\
\end{array}$ \\
\hline & & $\begin{array}{lllll}\text { XIV. } & 417 & 28 & 14 & 28\end{array}$ \\
\hline 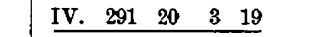 & & XIV. 413 53(neg.) 10 \\
\hline
\end{tabular}


RELATION BETWEEN SPIROCHAETA PALLIDA FROM OLD LESIONS, SURVIVAL IN TESTICLE AND INCUBATHON PERIOD

Cyclic changes in testicular lesions have been noted in our series of experiments, and this phase of the study will not be considered here in view of the thorough analysis which has been given in the work of Brown and Pearce. ${ }^{9}$ Periodic fluctuations in the spirochetal content of lesions such as they have described seem to be associated regularly with syphilis in rabbits, as our own studies have demonstrated. Whether or not these cyclic changes go hand in hand with other factors is of importance primarily from the standpoint of possible differences in infectivity of organisms taken from lesions at different times when the incubation period and survival under a set of conditions may be compared.

The age of a lesion at the time transfers were made to new series of animals did not affect the period of incubation or the survival of spirochetes within the testicles of succeeding generations of rabbits. It would appear that Spirochaeta pallida assumes a condition of latency not devoid of its original infective properties. Furthermore, in several instances in which different amounts of organisms were used for inoculation, no departure from the norm was to be detected. These observations become more significent and more easily interpreted in connection with the protective properties of serums obtained during both the active and latent stages of experimental syphilis, a study which will be reported subsequently.

Spirochactae pallidae were recovered for variable periods of time up to more than four and a half months when this paper was written. Subinoculations were made at intervals anywhere from one day to more than ten weeks after organisms were first demonstrated in the testicle. In Tables 5 and 6 are given some of the observations which show at a glance that no correlation exists between the age of the lesion or the spirochetal content of such lesions and the survival within the focus of infection. Whether or not the spirochetes which were used for inoculating new series of animals were fresh or old, did not appear to influence adaptation to the testicle as measured by survival, or to affect the period of incubation.

\section{TYPES CF LESIONS}

The syphilitic manifestations which were observed in the testicles of rabbits were, with certain exceptions, not constant for any of the strains used in this study. There were variations from a diffuse or interstitial orchitis to a circumscribed induration with all possible gradations

9. Brown, W. H., and Pearce, L.: J. Exper. Med. 31:709 (June) 1920. 
between. Within any series these differences could be observed. In one generation from a chancre strain, for example, a diffuse swelling would occur, only to be followed by a nodular type of lesion, or the reverse might be true. Compact infiltration was followed invariably by regression in which small nodules became palpable and subsequently disappeared. At other times a definite cycle was manifested. In these instances induration would be followed by the development of circumscribed areas a week or more after marked regression had become apparent. Thus the persistence of Spirochaeta pallida in the puncture material obtained from testicles did not bear any relation to the type of lesion and its cycle, other than a longer period of survival such as would naturally be the case in a chronic or proliferative type of lesion which seemed to be associated invariably with the strains of Spirochaeta pallida isolated from glands of patients with latent syphilis. Barring this outstanding difference in behavior, nothing unusual was noted in the remaining strains.

Table 5.-Strain 137. Survival of Spirochaeta Pallida in Testicle*

\begin{tabular}{|c|c|c|c|c|c|c|c|c|c|c|c|c|c|c|c|}
\hline \multicolumn{16}{|c|}{$\begin{array}{l}\text { Age of Lesion } \\
\text { (Days) } \\
\text { at Time of }\end{array}$} \\
\hline $70-75$ & .. & .. & .. & .. & + & .. & .. & .. & .. & .. & .. & .. & .. &.. &.. \\
\hline $26-30$ & .. & . & . & .. & .. & .. & .. & .. & .. & .. & .. & .. & . & .. &.. \\
\hline 21-25 & .. & $\because$ & $\ddot{t}$ & $\cdots$ & $\cdots$ & $\cdots$ & .. & $\because *$ & .. & .. & .. & .. & .. & .. & . \\
\hline $16-20$ & .. & + & + & .. & $\cdots$ & .. & .. & $+^{*}$ & $\cdots$ & .. & . & .. & . & . & .. \\
\hline $11-15$ & & + & .. & .. & $\cdots$ & $\cdots$ & .. & .. & .. & .. & . & .. & .. & .. & .. \\
\hline $6-10$ & + & + & .. & $\ddot{i}$ & $\cdots$ & $\cdots$ & .. & . & .. & .. & + & .. & .. & .. &.. \\
\hline $1-5$ & $\dddot{t}$ & $\begin{array}{r}+ \\
+(d)\end{array}$ & 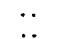 & $\begin{array}{l}++ \\
++\end{array}$ & $\ddot{+*}$ & $\because$ & .. & .. & $\ddot{+}$ & $\because$. & $\ddot{t}^{*}$ & $\dddot{t}$ & $\ddot{+}$ & $\dddot{t}$ & $\ddot{t}^{*}$ \\
\hline Days & $1-5$ & $6-10$ & $11-15$ & $\begin{array}{c}16-20 \\
16-1\end{array}$ & $21-25$ & $26-30$ & $31-35$ & $36-40$ & $51-55$ & $56-60$ & $61-65$ & $66-70$ & $91-95$ & $8-100$ & 20130 \\
\hline
\end{tabular}

* In Tables 5 and $6+$ indicates individual observations, * incomplete observations, and (d), died.

Table 6.--Strain 170. Survival of Spirochaeta Pallida in Testicle

\begin{tabular}{|c|c|c|c|c|c|c|c|c|c|c|c|c|c|c|c|}
\hline \multicolumn{16}{|l|}{$\begin{array}{c}\text { Age of Lesion } \\
\text { (Days) } \\
\text { at Time of } \\
\text { Subinoculation }\end{array}$} \\
\hline $\begin{array}{l}46-50 \\
41-45\end{array}$ & .. & $\ddot{t}$ & $\therefore$ & .. & $\because$. &. & $\because$. & .. & . & $\because$ & .. & . & .. & .. & 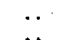 \\
\hline $\begin{array}{l}41-45 \\
36-40\end{array}$ & $\because$. & $\begin{array}{l}+ \\
.\end{array}$ & ... & $\ddot{t}$ & $\because$. & .. & $\ddot{x}$ & $\because$ & $\dddot{t}$ & .. & .. & $\because$ & $\because$. & 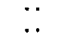 & $\because$. \\
\hline $31-35$ &. &.. &.. & $\because$ & .. & .. & $\therefore$ & 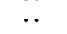 & .. &.. & . &.. &.. & .. & + \\
\hline $26-30$ &. & $\because$ & $\because$ & $\cdot$. & $\cdot \cdot$ & .. & .. & 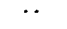 & .. & .. & $\because$ & .. & .. & .. &.. \\
\hline 21-25 & $\because$ & +7 & $\therefore$ & & $\cdots$ & .. & .. & $\cdots$ & $\because$ & .. & + & . & $\cdots$ & .. & .. \\
\hline 16-20 & + & + & $\cdot \cdot$ & ++ & $\cdots$ & .. & $\cdot \cdot$ & $\cdot \cdot$ & + & . & . & . & . & .. & . \\
\hline $\begin{array}{r}11-15 \\
6-10\end{array}$ & $\begin{array}{l}. . \\
.\end{array}$ & $\ddot{+}+$ & $\because$ & $\because$. & $\because$. & $\dddot{+}$ & .. & $\dddot{i}$ & .. & $\because$. & $\because$ & $\because$ &.. & $\because$. & $\ddot{n}$ \\
\hline Days & $\stackrel{+}{1-5}$ & ${ }_{6-10}^{+}$ & $\begin{array}{c}++ \\
11 \cdot 15\end{array}$ & $\ddot{16-20}$ & $\stackrel{+}{21-25}$ & $2 \ddot{6-30}$ & $31-35$ & $\begin{array}{l}+40 \\
36-40\end{array}$ & 41045 & $4 \ddot{6-50}$ & $51-55$ & $56-60$ & $\begin{array}{c}++ \\
61-65\end{array}$ & $\stackrel{+}{+}-70$ & $70-75$ \\
\hline
\end{tabular}

Lesions resembling chancres in certain respects occurred in six instances-in three strains isolated from primary chancres and three times with a strain of spirochetes isolated from a latent source. This strain was of special interest from the standpoint of spontaneous 
inoculation of the opposite testicle in the course of the infection. The development of scrotal chancres was observed on three occasions following intratesticular inoculation of the opposite testicle. One rabbit which had been inoculated with a strain in the seventh generation gave a positive reaction after an incubation period of thirty-four days. The iesion was confined to the upper pole of the left testicle and was

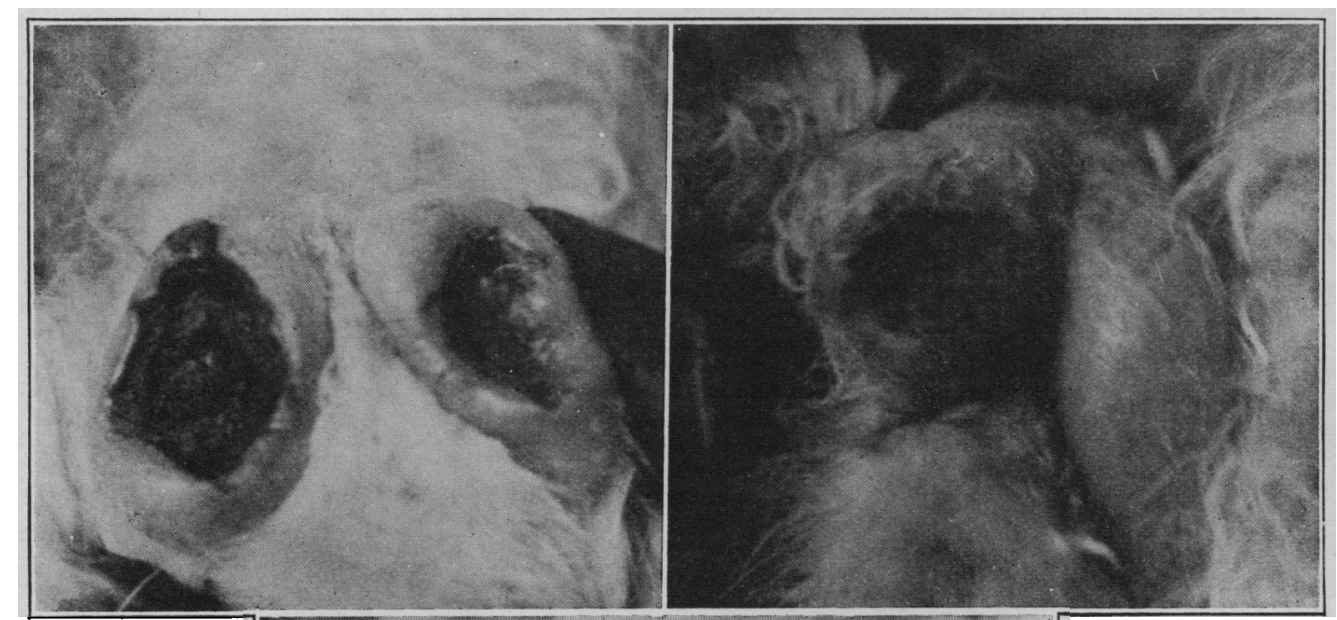

Figure 1

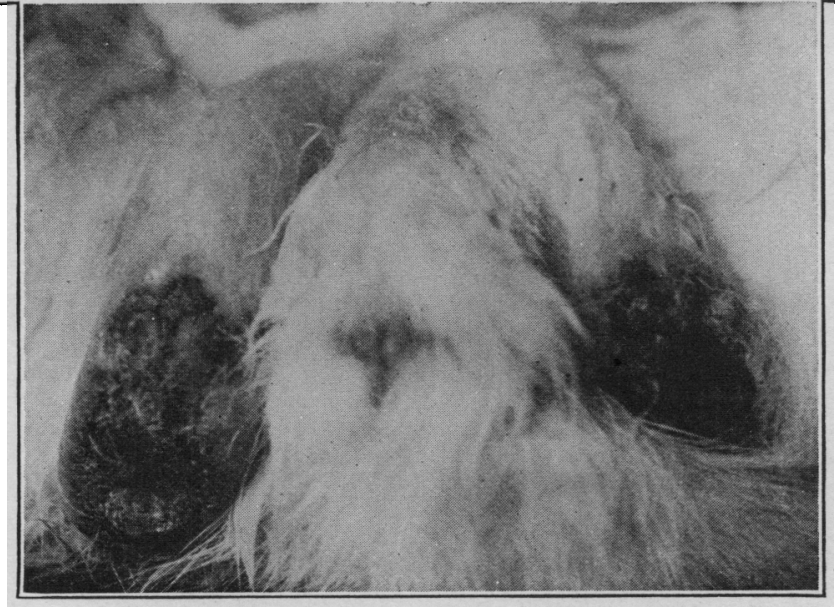

Figure 2

Figure 3

Scrotal infections in the course of active processes in opposite testicles.

nodular in type. Six weeks later a chancre, 1.5 by $3 \mathrm{~cm}$., developed on the scrotum of the right testicle. Two weeks later, the originally infected testicle presented a chancre-like lesion immediately adjacent to the primary lesion (Fig. 1). The second example of this nature occurred in an animal which had been inoculated similarly with the strain of a like generation from another series. The original lesion in the left testicle first appeared as a circumscribed nodu'e nineteen days 
after inoculation, and forty days later the right testis showed a scrotal chancre measuring 1 by $3 \mathrm{~cm}$. (Fig. 2). A third instance of chancrous lesions with this strain occurred in the eighth generation which represented a subinoculation from the preceding animal just mentioned. A nodular lesion, developing after an incubation period of twenty-five days, was followed thirty-one days later by a scrotal chancre at the original site of infection. Ten days later a similar scrotal lesion occurred at the lower pole of the testicle. The fourth example of autoinoculation occurred in the fourteenth generation of a chancre strain. A nodular lesion developed at the upper pole of the left testicle twenty-three days after inoculation. Eight weeks later a scrotal chancre, 1 by $1.5 \mathrm{~cm}$., was noted at the lower pole of the same testicle and on the right a chancre 1 by $2 \mathrm{~cm}$. with an indurated border about 4 mm. in thickness (Fig. 3). The remaining two examples of this nature may be dismissed briefly with the observation that it is possible for a scrotal lesion to develop soon after the appearance of a lesion within the testicle, in fact, in one instance a primary manifestation appeared after twenty-eight days' incubation.

REINOCULATION EXPERIMENTS AND THE POSSIBLE INFLUENCE OF SENSITIZATION

The autoinoculations which have been mentioned and the wellknown phenomenon of scrotal lesions occurring subsequent to intratesticular injection of Spirochaeta pallida are suggestive of the possible importance which might be attributed to the sensitization of certain tissues in the animal body during active infection with syphilis. Our knowledge of the mechanism by which syphilitic gummas are developed is indicative of a sensitizing process in which spirochetal cell-products or toxins play a part. In the rabbit testicle the purely local immunity of an infectious process is sharply defined by the manner in which new crops of lesions appear adjacent to involved areas. Chancre-like lesions, such as have been described in this paper and in the work of Brown and Pearce, seem to conform to a picture of necrosis and sloughing and, in general, to possess the characteristics of a true secondary manifestation. In a more striking way the involvement of the scrotum adjacent to testicular foci lends itself to a similar interpretation. Although this phase of the study could not be entered into with the degree of completeness desired, a small series of experiments gave results sufficiently uniform to merit some discussion. Attempts to infect the opposite testicle in the course of active involvement, during the stages of marked regression, and after almost complete disappearance of palpable lesions in one testicle, resulted in the development of chancre-like lesions in the other, without giving rise at any time to the 
characteristic process following intratesticular inoculation. A series of eight rabbits was injected in the normal testicle with material taken at different times from their respective infected testicles. Another series included animals that received homologous Spirochaeta pallida taken from other rabbits. The strain used was isolated from the inguinal gland of a case of latent syphilis. In the first group, 50 per cent. of the animals developed lesions in the subsequently inoculated testicle and in the second group, 75 per cent. The incubation period averaged from five to five and a half weeks. Dark-field examinations were characterized uniformly by a relative paucity of organisms. The scrotal lesions disappeared in from ten days to three weeks. Whether or not similar results may be obtained by the use of heterologous strains of spirochetes in an analogous manner is not known, since the object of the experiments was to determine roughly the infectivity of Spirochaeta pallida with a set of conditions tending to throw light on certain immune reactions. The outstanding feature of the experiments seems to be that the elaboration of syphilitic antibodies is not at its height early in the course of infection. This idea is borne out by studies on the protective properties of serum obtained from active and latent syphilis.

\section{SURVIVAL OF SPIROCHAETA PALLIDA IN COMPLETELY HEALED TESTICLES OF RABBITS}

Variations from the usual type of testicular infection in rabbits occur frequently. In some animals, at irregular times, slight changes may be found after inoculation with material from an actively infectious testicle, and again there are numerous instances of apparent failure to produce a "take." Influences which may modify the results of transfer from animal to animal have beẹn discussed already, and attention will be given now to examples of "latent" Spirochaeta pallida in testicles which have proved continually negative by puncture for long periods, coincident with total disappearance of lesions, and in testicles which have remained negative for indefinite periods without having shown lesions or spirochetes at any time. In four instances we have succeeded in isolating Spirochaeta pallida from suspensions prepared with macerated testicles of rabbits which had been found negative by puncture and free from visible or palpable lesions for a period of from four to five months; twice in rabbits carrying a strain of spirochetes isolated from an inguinal gland of a patient with latent syphilis (Strain 137), once from a rabbit with a strain isolated from the semen of a latent syphilitic patient (Strain 117), and again from an animal which had been inoculated with spirochetes from a penile chancre. 
SPIROChaEta Pallida in testicles Negative by PUNCTURE AND FREE FROM LESIONS

That certain conditions as they exist in the experimental animal may be paralleled in patients and deductions drawn accordingly would follow from the observations made in cases of latent syphilis ${ }^{1}$ and in some of the present work. The tendency for Spirochaeta pallida to assume a dormant or latent state in the body is now an established fact. A brief consideration of the behavior of a single strain of organisms which has been studied intensively in our work may add more data from the immunologic standpoint. A group of rabbits representing the sixth generation of "latent strain 137" was characterized by progressively diminishing lesions and a pronounced tendency toward a negative picture in the testicle, irrespective of the character as to age and amount of material taken for subinoculation from the previous generations. Four.animals which had been inoculated with spirochetecontaining material from a rabbit in the sixth generation series failed to develop any lesions and were found negative by puncture for more than four months. A rabbit from this group was castrated and an emulsion of the inoculated testicle injected into the testicle of another rabbit which remained negative for a period of six weeks. This animal was castrated and the testicular emulsion injected into a third rabbit which developed a minute nodule after five weeks. The lesion, about $2 \mathrm{~mm}$. in diameter, did not increase in size and was found to contain spirochetes over a period of two weeks when the lesion disappeared.

TABLE 7.-Summary of Protocols

$\begin{array}{ccccc}\text { Strain } & \begin{array}{c}\text { Old Series } \\ \text { Incubation } \\ \text { Period } \\ \text { Days }\end{array} & \begin{array}{c}\text { Survival of } \\ \text { Spirochetes } \\ \text { Days }\end{array} & \begin{array}{c}\text { Days } \\ \text { Negative }\end{array} & \begin{array}{c}\text { Subinoculations } \\ \text { Incubation } \\ \text { Period } \\ \text { Days }\end{array} \\ 137 & 28 & 22 & 116 & 34 \\ 137 & 35 & 66 & 138 & 48 \\ 117 & 28 & 31 & 116 & 42 \\ 169 & 30 & 29 & 120 & 41 \\ & & & & \end{array}$

The infectivity of Spirochaeta pallida derived from old lesions was not diminished by prolonged residence in an infected focus. No correlation seemed to exist between the period of incubation of the organism, on one hand, and the age of the lesion from which it was obtained, on the other.

Survival of Spirochaeta pallida in experimental syphilis was subject to marked variation. The persistence of spirochetes in rabbits' testicles was not correlated with the period of incubation, with the age 
of the lesion, or with the number of animal passages of the different strains studied. Incomplete observations show that they may be present for more than five months.

Spirochetal content of lesions in the testicle was not correlated with the age of lesions and survival within the focus of infection. Fresh as well as old spirochetes did not appear to influence adaptation to environment as measured by survival, or to affect the period of incubation. No differences have been found to exist between different "lines of descent" made from a series of animals which represented transfers from actively developing lesions, and a series of generations which were derived from animals having old regressive lesions.

Although syphilitic manifestations in the rabbit testicle may exhibit a wide range of variability in their cyclic changes, certain outstanding features may be associated with definite strains of Spirochaeta pallida. A chronic proliferative type of reaction characterized organisms which had been isolated originally from cases of latent syphilis. The type of lesion, however, did not give an indication as to the fate of Spirochaeta pallida in such lesions. Scrotal lesions following as late manifestations of old testicular infection were not referable to particular strains.

Elaboration of syphilitic antibodies appeared to be at a maximum late in the course of infection and predisposed to a condition of latency in which, despite the absence of lesions, Spirochaeta pallida could be demonstrated. Far from preventing reinoculation with Spirochaeta pallida, a state of resistance appears to favor the localization of organisms in tissues without giving rise to manifest lesions.

Inoculated testicles which remained negative for indefinite periods, presenting no lesions, and proving negative by puncture, have been found to harbor Spirochaeta pallida capable of infecting other animals. The tendency for a condition of latency to occur was confined to certain strains of organisms, in particular those which had been isolated from latent sources in patients and rabbits.

In the absence of lesions and with negative dark-field findings over a period of four to five months, Spirochaeta pallida was isolated from apparently normal testicles which had previously been positive for spirochetes.

Sensitization phenomena may play an important part in the production of a certain kind of scrotal lesion resulting from autoinoculation of a normal testicle, from experimental infection of the opposite testicle in the course of involvement of the other, or from old testicular foci.

Seven strains of Spirochaeta pallida have been studied from the standpoints of infectivity and survival and differential characters. Five of the strains were isolated from cases of latent syphilis-inguinal glands and semen-and the others were obtained from penile chancres. 